\title{
Optimization of Microwave-Assisted Extraction of Active Com- pounds, Antioxidant Activity and Angiotensin Converting En- zyme (ACE) Inhibitory Activity from Peperomia pellucida (L.) Kunth
}

\author{
Abdul Mun'im', Siti Nurpriantia', Ririn Setyaningsih', Rezi Riadhi Syahdi² \\ 'Department of Pharmacognosy-Phytochemistry, Faculty of Pharmacy, Universitas Indonesia, Gedung A Rumpun Ilmu Kesehatan Lantai 3, Kampus UI Depok, 16424, \\ West Java, INDONESIA. \\ ${ }^{2}$ Department of Medicinal Chemistry, Faculty of Pharmacy, Universitas Indonesia, Gedung A Rumpun IImu Kesehatan Lantai 3, Kampus UI Depok, 16424, West Java, \\ INDONESIA.
}

\begin{abstract}
Introduction: to obtain the optimum extraction conditions of total phenolic content (TPC), total flavonoid content (TFC), antioxidant activity (AA) and angiotensin converting enzyme (ACE) inhibitory activity from Peperomia pellucida (L.) Kunth. Method: TPC, TFC, AA and ACE inhibitory activity was measured by Folin-Ciocalteu method, $\mathrm{AlCl}_{3}$ method, DPPH and FRAP methods, and ACE kitWST. MAE efficiency parameters used were ethanol concentration, a sample to solvent ratio, extraction time, and microwave power. Results: The optimum conditions of MAE for TPC (49.78 mg GAE/g extract) and TFC (37.18 mg OE/g extract) were $80 \%$ ethanol, sample-solvent ratio of $1: 12$, extraction time of $2 \mathrm{~min}, \mathrm{MAE}$ power of $30 \%$ and $80 \%$ ethanol, ratio of $1: 12$, time of $2 \mathrm{~min}$, and $70 \%$ power respectively. The optimum AA was obtained at $65 \%$ ethanol, ratio of 1:10, time of $3 \mathrm{~min}, 50 \%$ power (DPPH method), and $65 \%$ ethanol, the ratio of $1: 12$, time of $1 \mathrm{~min}$, and $70 \%$ power (FRAP method) respectively. The optimum ACE inhibitory activity $(54.73 \%$ at a concentration of $100 \mu \mathrm{g} / \mathrm{mL}$ ) were obtained at $80 \%$ ethanol, ratio of $1: 12$, time of $2 \mathrm{~min}$, and $70 \%$ power.
\end{abstract}

Conclusion: The analysis of Pearson correlation indicated that there was no correlation between TPC with FRAP method; TPC with ACE inhibitory activity and TFC with DPPH method

Key words: ACE, Antioxidant Activity, Flavonoid Compounds, Microwave-Assisted Extraction, Peperomia pellucida (L.) Kunth, Phenolic Compounds.

Correspondence :

Abdul Mun'im

Department of Pharmacognosy-Phytochemistry, Faculty of Pharmacy, Universitas Indonesia, Gedung A Rumpun IImu Kesehatan Lantai 3, Kampus UI Depok, 16424, West Java, INDONESIA.

Phone no: +628111184550

Email: munim@farmasi.ui.ac.id

DOI: 10.5530/jyp.2017.1s. 19

\section{INTRODUCTION}

Peperomia pellucida (L.) Kunth is medical herb of Piperaceae that grows in damp places and is widely available in countries America and Asia including Indonesia. ${ }^{1}$ The ethanolic extract of $P$. pellucida contains alkaloids, saponins, tannins, flavonoids, terpenoids, and cardiac glycosides. ${ }^{2}$ From the previous research, phenolic compounds such as flavonoids and tannins reported having antioxidant activity and the ACE inhibitory caused by phenolic groups. The optimum content to obtain of phenolic compounds, flavonoid compounds activity as ACE inhibitors and antioxidants activity of herbal extracts necessary appropriate extraction method. Extraction with conventional methods produce inferior products and needs a lot of solvents, energy and time. ${ }^{3}$ Modern methods such as microwave-assisted extraction (MAE) becomes with benefits, among others results higher extraction, extraction time is short and a little solvent consumption. ${ }^{3}$ There are factors that the efficiency MAE extraction with the irradiation time, the volume and concentration of the solvent, and microwave power. ${ }^{4}$ The optimizing of MAE need four factors. Response surface methodology (RSM) is a mathematical techniques and statistics in this case can investigate the relationship between the variables of extraction and the results, as well as to optimize the experimental variable. Compared factorial design, experimental design with RSM more efficient in reducing the number of experiments carried out and the time required for optimizing the extraction conditions. ${ }^{5}$ In this study used RSM to obtain extraction conditions optimum of phenolic compounds, flavonoid compounds, ACE inhibitory activity, and antioxidants activity. In this study is expected to obtain optimum conditions MAE of total phenolic content, the flavonoid content, ACE inhibitory activity and antioxidant using RSM.

\section{MATERIALS AND METHODS}

\section{Materials}

\section{Plants materials}

Peperomia pellucida (L.) Kunth obtained from Balai Penelitian Tanaman Obat dan Aromatika (BALITRO), Bogor. The herbs were stored in drying cabinets and sorted then powdered by a grinding machine to obtain a dry powder.

\section{Materials and reagents}

Gallic acid, quercetin, 1,1-diphenyl-2-picrylhydrazyl (DPPH), sodium carbonate and 2,4,6-Tri(2-pyridil)-s-triazine (TPTZ) were purchased from Sigma-Aldrich. Folin-Ciocalteu, dimethyl sulfoxide, sodium acetate, iron (III) chloride, hydrochloric acid, glacial acetic acid, methanol and ethanol (pro analysis) were purchased from Merck. ACE kit-WST 
was purchased from Dojindo, Japan. Captopril was obtained from Kimia Farma, Indonesia. Distilled ethanol comes from Brataco.

\section{Methods}

\section{Extraction and experimental design}

The herbs powder $(20 \mathrm{~g})$ extraction with MAE method was performed using ethanol-water in a $1000 \mathrm{~mL}$ round bottom flask. The extraction was adjusted based on parameters such as concentrations of solvent extraction, extraction time, sample ratio of the solvent, and MAE power. The extraction parameters were optimized using response surface methodology (Design Expert software version 10.0.2.0) with Box-Behnken experimental design. ${ }^{3}$ All parameters were independent variables which the value ranges were selected based on preliminary test results. Three levels of each variable coded as $-1,0$, and +1 . Then extract was filtered and evaporated using rotary vacuum evaporator.

\section{Determination of total phenolic content (TPC)}

Determination of TPC was performed by spectrophotometric method used the Folin-Ciocalteu reagent according to Shah et al (2016) with slight modification, and the results were expressed in $\mathrm{mg}$ gallic acid equivalents per $g$ of the extract (mg GAE/g extract). ${ }^{6}$ An aliquot (0.5 $\mathrm{mL}$ ) of diluted sample was mixed with $2.5 \mathrm{~mL}$ of $10 \% \mathrm{v} / \mathrm{v}$ Folin-Ciocalteu reagent, then was vortex and incubated for $2 \mathrm{~min}$ at $25^{\circ} \mathrm{C}$. After that, 2.0 $\mathrm{mL}$ of $7.5 \% \mathrm{w} / \mathrm{v} \mathrm{Na}_{2} \mathrm{CO}_{3}$ was added. The solution was vortex and incubated at $25^{\circ} \mathrm{C}$ for $60 \mathrm{~min}$. The absorbance of the mixture was measured at $765 \mathrm{~nm}$ against the blank solution using a UV-Vis spectrophotometer. The blank solution contains a mixture of reagents and solvents without the sample. Total phenolic levels are determined using a standard calibration curve of gallic acid. ${ }^{6,7}$

\section{Determination of total flavonoid content (TFC)}

Total flavonoid content was measured using $10 \% \mathrm{AlCl}_{3}$ with some modifications. ${ }^{9}$ The extract $(25 \mathrm{mg})$ was diluted in $25 \mathrm{~mL}$ of methanol, 0.5 $\mathrm{mL}$ aliquot of the diluted sample was mixed with $1.5 \mathrm{~mL}$ methanol, 0.1 $\mathrm{mL}$ of $10 \% \mathrm{AlCl}_{3}, 0.1 \mathrm{~mL}$ of $1 \mathrm{M}$ sodium acetate, and $2.8 \mathrm{~mL}$ distilled water. The mixture was vortex and incubated for 30 minutes at $37^{\circ} \mathrm{C}$. The absorbance of the mixture was measured at $415 \mathrm{~nm}$ with a UV-VIS spectrophotometer. Quercetin was used as a reference standard, and the results were expressed as $\mathrm{mg}$ of quercetin equivalents $(\mathrm{QE})$ per $\mathrm{g}$ of the extract (mg QE/g extract).

\section{Determination of radical scavenging activity by the DPPH method}

Radical scavenging activity was determined by using DPPH method. ${ }^{10,11}$ Dry extract was dissolved in methanol. The diluted sample $(1 \mathrm{~mL})$ was reacted with $1 \mathrm{~mL}$ DPPH $(150 \mathrm{ppm})$ and $2 \mathrm{~mL}$ of methanol. The mixture was vortex and incubated in the dark for 30 minutes at $37^{\circ} \mathrm{C}$. The absorbance was measured with spectrophotometer UV/Vis at $515 \mathrm{~nm}$. Quercetin was used as a reference standard.

\section{Determination of antioxidant activity (AA) by the FRAP method}

Ferric Reducing Antioxidant Power (FRAP) assay was performed according to the Benzie and Strain (1999) method with some modifications. ${ }^{12}$ Brieftly, an aliquot of extracted sample $(100 \mathrm{~L})$ was added with $3.0 \mathrm{~mL}$ of FRAP reagent in test tubes, then homogenized. Both samples and blank were incubated in water bath for $30 \mathrm{~min}$ at $37^{\circ} \mathrm{C}$. Then, the sample absorbance was measured against blank FRAP using spectrophotometer UV/Vis at $595 \mathrm{~nm}$. Series of stock solution at 24, 30, 66, 78, 120 , $150 \mu \mathrm{M}$ were prepared using ethanol of Gallic acid as standard calibration curve. AA of the sample was expressed as $\mu \mathrm{mol}$ of gallic acid equivalent per $g$ of extract ( $\mu \mathrm{mol} \mathrm{GAE/g} \mathrm{extract)} .^{13}$

\section{ACE inhibition assay}

ACE inhibitory activity was measured using ACE kit-WST (Dojindo Laboratories, Japan) and captopril was used as a standard. The dried extract was dissolved in $\mathrm{ddH}_{2} \mathrm{O}$ to obtain a concentration of $100 \mathrm{~g} / \mathrm{mL}$. The testing procedures were performed strictly according to kit guidelines from the manufacturer using a 96-well plate without modification (Dojindo Laboratories, 2013). The assay used 3-hydroxybutyrate glycine (3HB-GGG) as a substrate for the screening of the ACE inhibition rate. The absorbance of resultant of the extract/standard sample was measured using micro plate reader (Thermo Scientific, USA) at $450 \mathrm{~nm}$. The ACE inhibitory activity was calculated based on the comparison of absorbance of the extract/standard sample (As), positive control (Ac), and reagent blank $(\mathrm{Ab})$ as in the equation below.

ACE Inhibitory Activity $(\%)=[(\mathrm{Ac}-\mathrm{As}) /(\mathrm{Ac}-\mathrm{Ab})] \times 100$

\section{Thin layer chromatography (TLC) method}

TLC profile of the extracts were determined by TLC densitometry using silica plate (Merck, Germany) as stationary phase and dichloromethane: methanol (90:10) mixture as mobile phase. The plate which has been eluted then we analyzed using densitometer (Camag, Swiss) at $254 \mathrm{~nm}$ and $366 \mathrm{~nm}$.

\section{RESULTS}

\section{Selection of extraction parameters}

The parameter of extraction conditions of MAE was determined through the study of literature. According to there were several factors that affect the efficiency of MAE, including the type of solvent, the samplesolvent ratio, extraction time and microwave power. The polar solvents such as ethanol-water was suitable to be used for extracting of phenolic compounds which were polar because generally these compounds bind to sugar compounds as glycosides. Independent variables and levels as shown in Table 1. Based on those variables and levels, there are a total 25 run experiments.

\section{Total phenolic content}

Graph of TPC of each sample is shown in Figure 1. Based on the graph, it appears that the run 20 gives the average level of the highest, namely $49.78 \mathrm{mg} \mathrm{GAE} / \mathrm{g}$ extract, with solvent extraction conditions such as $80 \%$ ethanol, the sample-solvent ratio of 1:12, extraction time of $2 \mathrm{~min}$, and $30 \%$ microwave power. TPC of $P$. pellucida extract obtained in this study $(49.78 \pm 1.15 \mathrm{mg} \mathrm{GAE} / \mathrm{g}$ extract) was quite high when compared with the methanol extract at reflux method $(35.79 \pm 1.10 \mathrm{mg} \mathrm{GAE} / \mathrm{g}$ extract). Meanwhile, when compared with maceration method $(25.09 \pm 0.53 \mathrm{mg}$ GAE/g extract), the MAE method also greater yield in TPC. Run 20 was the optimum conditions MAE of total phenolic compounds in the herbs. This indicated that the MAE method was an efficient method to obtain the content of phenolic compounds in the plants.

\section{Thin layer chromatography profile}

Figure 2 showed TLC profile of the extract. The results of densitometry at a wavelength of $366 \mathrm{~nm}$ shows a sample run 23 and quercetin which has the biggest spot at $\mathrm{R}_{\mathrm{f}}$ of $0.28(1.56 \%)$ and $0.5(7.77 \%)$, respectively. The presence of flavonoid in $P$. pellucida were clarified by TLC profile after stained by $\mathrm{AlCl}_{3}$ solution.

\section{Determination of the total flavonoid content (TFC)}

Figure 3 showed effect of MAE conditions on total flavonoid content. MAE optimum conditions for the extraction of total flavonoid content is run 23 . Run 23 consists of $80 \%$ ethanol solvent, the sample-solvent ratio of $1: 12,2$ minutes, and power 70 . 


\section{Free radical scavenging of $D P P H$}

Free radical DPPH scavenging activity of each extract after MAE extraction was presented in Figure 4. Run 1 is the optimum extraction conditions with reduction of the free radical DPPH value of $28.55 \%$. The extraction conditions in run 1 in the form of ethanol 65\%, a sample-solvent ratio of 1:10, extraction time of 3 minutes, and 50\% microwave power while run 8 with ethanol-water $50 \%$, the ratio of sample to solvent $1: 12$, time 2 minutes and 30\% power.

\section{Correlation between TFC and radical scavenging activity}

The results showed no significant relationship ( $\mathrm{p}>0.05$ ) between the levels of flavonoids to antioxidant activity DPPH method, with a correlation coefficient $r=0.41$. Correlation analysis between TFC and free radical DPPH scavenging activity was presented in Figure 5.

\section{Determination of antioxidant activity by FRAP method}

In this study, $\mathrm{EC}_{50}$ of Gallic acid that indicates the concentration needed to increase the uptake of 50\% was 5.29 M. From the graph of antioxidant capacity FRAP methods obtained from each run (Figure 6), it appears that the second run is the optimum extraction conditions with antioxidant capacity values $130.33 \pm 5.19 \mathrm{~mol} \mathrm{GAE} / \mathrm{g}$ extract. The extraction conditions in run 2 in the form of $65 \%$ ethanol, a sample-solvent ratio of 1:12, extraction time of $1 \mathrm{~min}$, and 70\% microwave power.

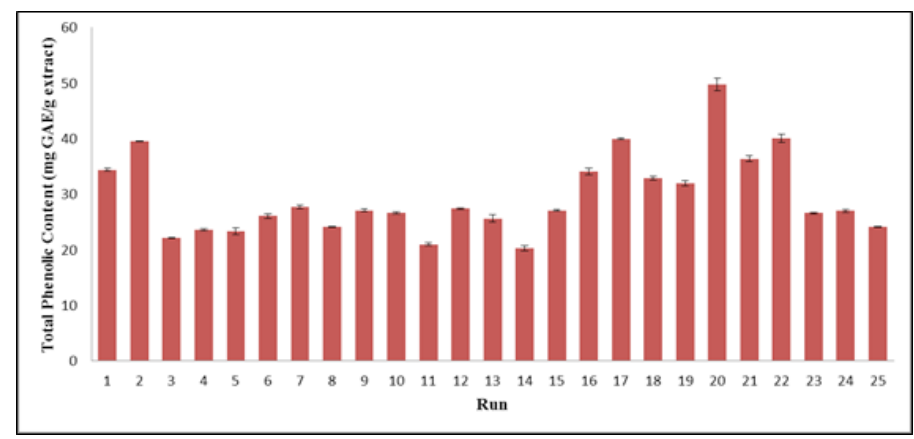

Figure 1: Graph of TPC from Peperomia pellucida (L.) Kunth extract $(n=3)$.
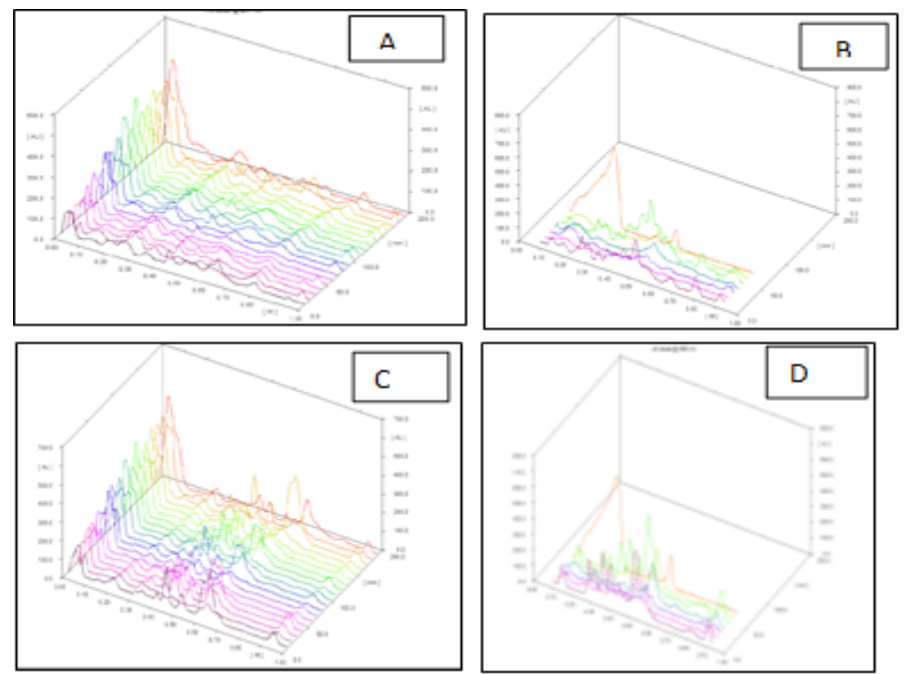

Figure 2: Thin layer chromatography profile of $P$. pellucida extract using densitometry (A) run 1-19 (B) run 20-kuersetin $254 \mathrm{~nm}$ wavelength (C)run 1-19 and (D) run 20-25 wavelength $366 \mathrm{~nm}$
Correlation between TPC with antioxidant capacity of FRAP method

The analysis showed that no significant relationship $(\mathrm{p}>0.05)$ between TPC and antioxidant capacity of FRAP method $(r=0.359)$ (Figure 7$)$, which means that the relationship positive, weak and not significant.

\section{ACE inhibition assay}

ACE inhibition activity assay was conducted on a sample extract with a concentration of $100 \mathrm{ppm}$, and captopril solution was used as a standard comparison with $\mathrm{IC}_{50}$ values of $1.13 \times 10^{-12} \mathrm{ppm}$. Run 23 provides the mean percent ACE inhibition above 50\%, which is $54.73 \%$ (Figure 8 ). Conditions such as solvent extraction run 23 to $80 \%$ ethanol, the samplesolvent ratio of 1:12, extraction time of 2 minutes, and $70 \%$ microwave power.

\section{Correlation between TPC with ACE inhibitory activity}

The correlation between TPC with ACE inhibitory activity of ethanolwater extract of $P$. pellucida was analyzed using Pearson correlation. In this research, the relationship was not significant $(p>0.05)$ between the total phenolic content of the percent inhibition of ACE ethanol-water extract of herbs errand $(r=0.322)$, which means that the relationship included in the category of weak (Figure 9).

When compared to the optimum MAE phenolic compounds, the difference MAE conditions for obtaining optimum ACE inhibitory activity lies only in the micro-wave power, which is $70 \%$. It is possible that the active compound as an ACE inhibitor is not just a phenolic compound, and at $70 \%$ power and extraction time of 2 minutes, the compound is not degraded.

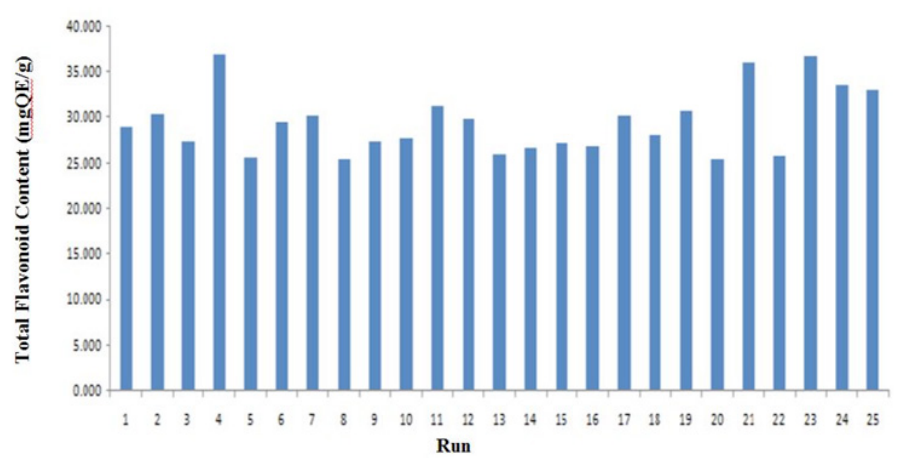

Figure 3: Total flavonoid content of P. pellucida (L.) Kunth extract of each MAE condition (Values are the mean of triplicate measurements).

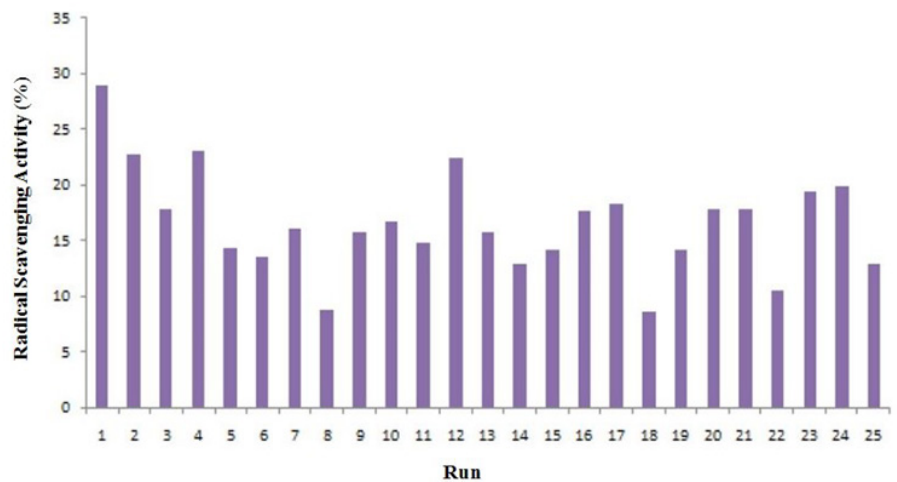

Figure 4: : Effect of MAE condition of P. pellucida extraction on DPPH free radical scavenging activity (Values are the mean of triplicate measurements).. 


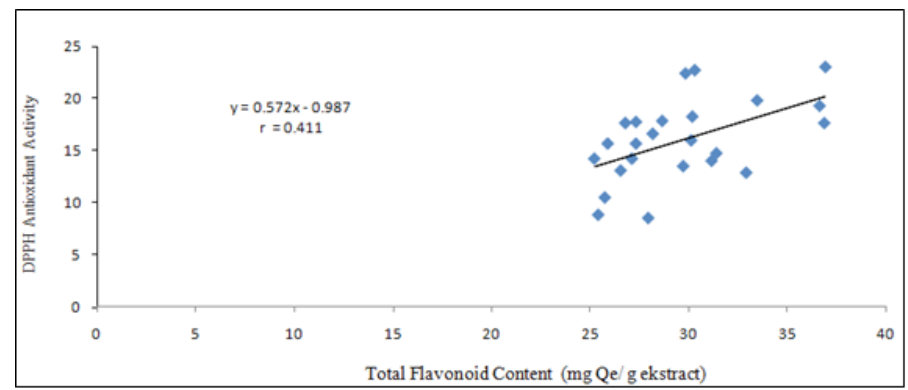

Figure 5: Curve correlation between total flavonoid content and the DPPH free radical scavenging activity.

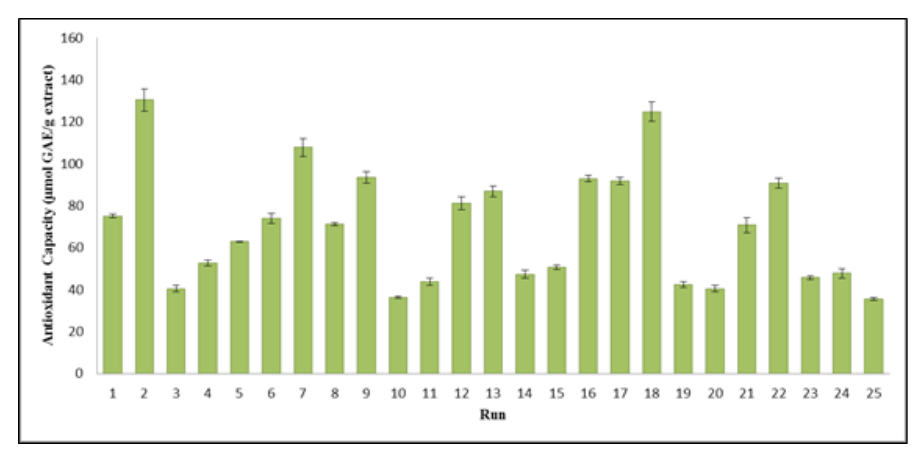

Figure 6: Antioxidant capacity value of FRAP method of P. pellucida extracts (Values are the mean of triplicate measurements).

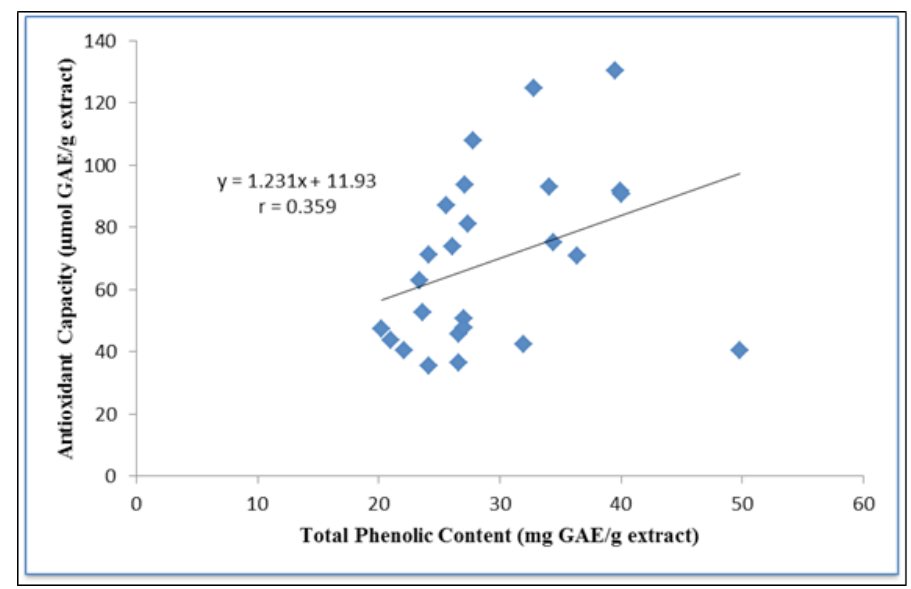

Figure 7: The relationship curve between TPC and antioxidant activity of FRAP method of P. pellucida extract.

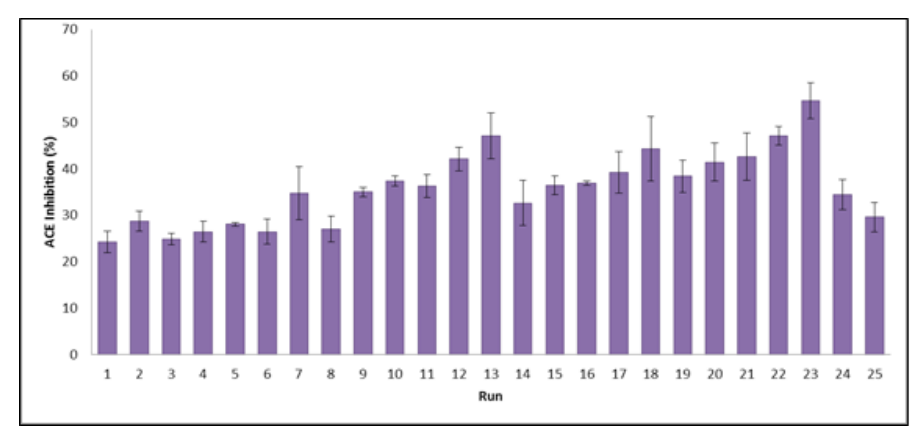

Figure 8: ACE inhibition percentage value of each P. pellucida extract (sample concentration $=100 \mathrm{ppm}$; values are the mean of triplicate measurements).

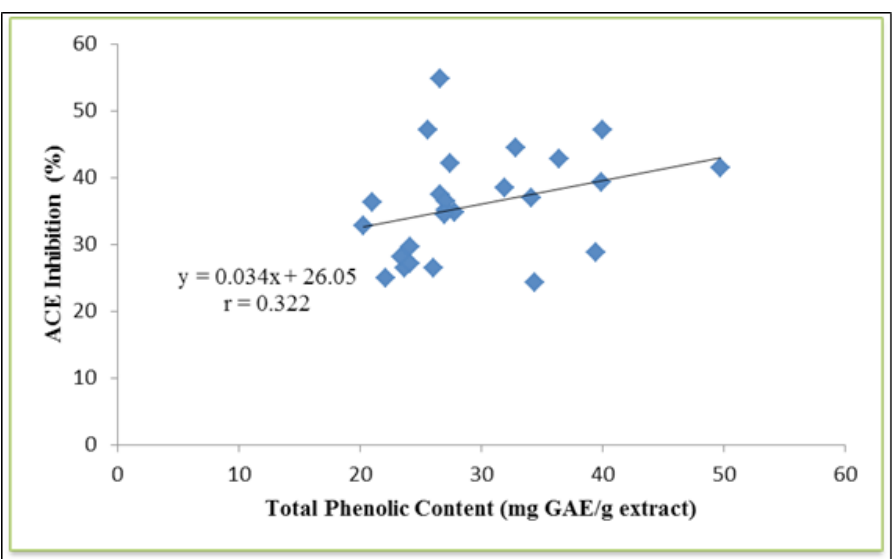

Figure 9: Relationship curve between TPC with ACE inhibition percentage of $P$. pellucida extract.

Table 1: Independent variables and their level

\begin{tabular}{ccccc}
\hline \multirow{2}{*}{ No. } & Factors & \multicolumn{3}{c}{ Levels } \\
\cline { 3 - 5 } & & -1 & 0 & +1 \\
\hline 1. & Ethanol concentration & $50 \%$ & $65 \%$ & $80 \%$ \\
2. & Sample to solvent ratio & $1: 10$ & $1: 12$ & $1: 14$ \\
3. & Extraction time & $1 \mathrm{~min}$ & $2 \mathrm{~min}$ & $3 \mathrm{~min}$ \\
4. & Microwave power & $30 \%$ & $50 \%$ & $70 \%$ \\
\hline
\end{tabular}

\section{DISCUSSIONS}

Peperomia pellucida is edible plant and traditionally used medicinal plant in Indonesia. The aerial part of this plat was used to decrease uric acid levels and to treat renal problems. Scientifically, this plant has been proven to demonstrate some biological activities, such as anti-inflammation, analgesic, and fracture healing. ${ }^{14,15}$ In the previous study, methanolic extract of this plant showed strong ACE inhibitory activity. ${ }^{16}$ This plant reported to contained flavonoid and phenolic compounds. ${ }^{16,17}$

MAE is advanced extraction technique which effective for extraction phytoconstituent. ${ }^{18}$ This technique has been successful extracted flavonoid and phenolic from plants. ${ }^{19,20}$ In this study ethanol-water mixture was selected as an extraction solvent because the mixture has a high dielectric constant and dissipation factor to absorb microwave energy effectively and was able to increase the penetration of the solvent into the sample matrix, and consequently, heating efficiency was increased. ${ }^{21} \mathrm{Re}$ search shows that the presence of a small amount of water in the solvent extraction increased the diffusion of water into the cell matrix, delivers better heating, and facilitates high-speed mass transfer compound into the solvent. ${ }^{7}$ Extraction time was selected based on heating efficiency with microwave and to avoid the risk of thermal degradation and oxidation of desired phenolic compounds. ${ }^{22}$

Polyphenols contribute to defend body on the complications involved with free radicals. Variations in the structure and level of phenolic compounds affect their antioxidant activity. Mechanism free radical scavenging DPPH method based electron donation from phenolic compound. ${ }^{11}$ Antioxidant activity using FRAP assay is based on a complex reduction of 2,4,6-tripiridil-s-triazine (TPTZ) with ferric chloride hexahydrate $\left(\mathrm{FeCl}_{3} \cdot 6 \mathrm{H}_{2} \mathrm{O}\right)$ are almost colorless to slightly brownish-yellow into blue ferro complex after reduction. ${ }^{12}$ In this study the gallic acid used as a reference standard because it is a phenolic acid compounds that have strong antioxidant activity. The results of this study indicated that nonphenolic compounds also play a role in providing antioxidant activity in ethanol-water extract of P. pellucida. According to Ou, Huang, Woodill, 
Flanagan, \& Deemer (2002), the above condition is difficult to find and unrealistic. It is caused by several factors, namely because of the potential value reduction of $\mathrm{Fe}$ (III)/Fe (II) was $0.77 \mathrm{~V}$, so that any compound including non-phenolic compounds with a potential value reduction below $0.77 \mathrm{~V}$ can reduce Fe (III) to Fe (II) and provides uptake value on FRAP methods, and keep in mind is that not all antioxidants can reduce $\mathrm{Fe}$ (III) at a time corresponding to the time of incubation. ${ }^{23}$

In this study, there is no correlation between total phenolic content with antioxidant activity. According to Grassmann (2005), is not only the phenolic compounds, but also vitamin $\mathrm{C}$, and vitamin $\mathrm{E}$ in fruit and vegetables also have antioxidant activity. ${ }^{22}$ Pigment such as chlorophyll, or nitrogen compounds can also act as antioxidants. Therefore, further research is needed to elucidate anti-oxidative compound in ethanol-water extract of $P$. pellucida.

Polyphenol and flavonoid in plant revealed potential ACE inhibitory activity. ${ }^{17,24}$ ACE inhibitory activity assay in the study was conducted using ACE-WST kit based on the enzymatic reaction that was initiated by $\mathrm{ACE}$ and aminoacylase in a mixture containing 3HB-GGG substrate and the sample as ACE inhibitors. During incubation, the substrate 3HBGGG enzymatically was broken into $3 \mathrm{HB}-\mathrm{G}$ and GG, then $3 \mathrm{HB}$ and G. $3 \mathrm{HB}$ formed was then observed through the concentration of formazan formed to produce a yellow color, absorbance was measured at $450 \mathrm{~nm}$ using a micro plate reader after $10 \mathrm{~min}$ at the reaction $25^{\circ} \mathrm{C} .{ }^{25}$ The results of this study indicated that the active compounds which have ACE inhibitory activity in ethanol-water extract of $P$. pellucida not only from phenolic compounds, because ACE has three active sides, where further study is needed on the compounds that can inhibit the activity of ACE. The first part is a carboxylate binding functionality such as guanidinium group of arginine. The second active side is a pocket which accommodates a hydrophobic side chains of C-terminal amino acid residues, and the third is a Zinc ion. In addition, the possibility of activity of ACE inhibitors on ethanol-water extract of $P$. pellucida more influenced by the content of flavonoids. The planar structure of the flavonoids important in inhibiting a metallopeptidase such as ACE. ${ }^{23}$ Study of structure-activity relationships of the flavonoid and inhibitory activity of ACE showed that the combination of sub-structures in the framework of flavonoids which enhances the activity of ACE inhibitor consists of the following elements: catechol group in the B-ring, a double bond between $\mathrm{C} 2$ and $\mathrm{C} 3$ on the C-ring, ketone group in C4 on the C-ring. ${ }^{25}$ Susmita \& De (2013) are also reported that the content of phenolic total on 19 kinds of fruit did not have a significant relationship with the percent inhibition of ACE, with a correlation value row $\mathrm{r}=0.0034$, and $\mathrm{r}=0.134 .^{26}$

\section{CONCLUSIONS}

The optimum conditions of microwave assisted-extraction for TPC were $80 \%$ ethanol, sample-solvent ratio of 1:12, extraction time of $2 \mathrm{~min}$, and microwave power of $30 \%$, while TFC were $80 \%$ ethanol, ratio of $1: 12$, time of $2 \mathrm{~min}$, and microwave power of $70 \%$. The result of study indicated that there was no significant correlation between TPC and ACE inhibitory activity and antioxidant activity. Also, there were no significant correlation between TFC and scavenging activity

\section{ACKNOWLEDGEMENT}

This study was supported by the ministry of research and technology, Republic of Indonesia and Directorate of Research and Community Engagement, Universitas Indonesia via Hibah PITTA 2016.

\section{CONFLICT OF INTEREST}

None.

\section{ABBREVIATIONS USED}

AA: Antioxidant activity; ACE: Angiotensin converting enzyme; DPPH: 1,1-diphenyl-2-picrcylhydrazil; MAE: Microwave assisted extraction; TFC: Total flavonoid content; TLC: Thin layer chromatography; TPC: Total phenolic content.

\section{REFERENCES}

1. Majumder P, Kumar KVA. Establishment of quality parameters and pharmacognostic evaluation of leaves of Peperomia pellucida (L.) HBK. Int J Pharm Pharm Sci. 2011;3(5):3-6.

2. Ojo OO, Ajayi SS, Owolabi LO. Proximate analyses and the antimicrobial activities of the aqueous and organic extracts of bark of Rauvolfia vomitoria and leaves of Peperomia pellucida. Int Res J Biochem Bioinforma. 2012;2(6):127-34.

3. Tekindal MA, Bayrak H, Ozkaya B, GencY. Box- behnken experimental design in factorial experiments: The importance of bread for nutrition and health. Turkish J F Crop. 2012;17(2):115-23.

4. Borkataky M. Antioxidant activity, total phenolic content and total flavonoid content of Perilla ocymoides Linn. Der Pharm Lett. 2015;7(5):69-72.

5. Kuo C, Chen B, Liu Y, Chang CJ, Deng T, Chen J, et al. Optimized UltrasoundAssisted Extraction of Phenolic Compounds from Polygonum cuspidatum. Mol Nutr Food Res. 2014;19(1):67-77.

6. Shah M, Kabir H, Hossain MM, Kabir I, Rahman M, Hasanat A. $\alpha$-Amylase inhibition and cyto toxic activities of ethanol extract of Steudnera colocasiifolia K. Koch leaves. J Young Pharm 2016;8(4):391-7. https://doi.org/10.5530/ jyp.2016.4.15.

7. Azlim AA, Ahmed JKC, Syed ZI, Mustapha SK, Aisyah M, Kamarul RK. Total phenolic content and primary antioxidant activity of methanolic and ethanolic extracts of aromatic plants' leaves 1. Int Food Res J 2010;17(4):1077-83.

8. Blainski A, Lopes GC, de Mello JCP. Application and analysis of the Folin Ciocalteu method for the determination of the total phenolic content from Limonium brasiliense L. Molecules. 2013;18(6):6852-64. https://doi.org/10.3390/ molecules18066852; PMid:23752469.

9. Roy P, Abdulsalam FI, Pandey DK. Antibacterial, and antidiabetic potential of two traditional medicinal plants of India: Swertia cordata and Swertia chirayita. Pharmacognosy Res. 2015;7(5):57-62. https://doi.org/10.4103/09748490.157997; PMid:26109789 PMCid:PMC4466770.

10. Pervin R, Afrin S, Sabrin F, Zohora US, Rahman MS, Islam KD. Antioxidant, antibacterial and brine shrimp lethality bioassay of Amoora cucullata, a mangrove plant. J Young Pharm. 2016;8(1):33-8. https://doi.org/10.5530/jyp.2016.1.8.

11. Mun'im A, Negishi O, Ozawa T. Antioxidative compounds from Crotalaria sessiliflora. Biosci Biotechnol Biochem. 2003;67(2):410-4. https://doi.org/10.1271/ bbb.67.410; PMid:12729010.

12. Benzie IFF, Strain JJ. The ferric reducing ability of plasma (FRAP) as a measure of antioxidant Power: The FRAP assay. Anal Biochem. 1996;239(1):70-6. https:// doi.org/10.1006/abio.1996.0292; PMid:8660627.

13. Irshad M, Zafaryab M, Singh M, Rizvi MM a. Comparative analysis of the antioxidant activity of Cassia fistula extracts. Int J Med Chem. 2012;2012:157125.

14. de Fátima Arrigoni-Blank M, Dmitrieva EG, Franzotti EM, Antoniolli AR, Andrade MR, Marchioro Marchioro M. Anti-inflammatory and analgesic activity of Peperomia pellucida (L.) HBK (Piperaceae). J Ethnopharmacol. 2004;91(2-3):215-8. https://doi.org/10.1016/j.jep.2003.12.030 ; PMid:15120441.

15. Tsofack F, Parvez M, Hubert J, Tewari D, Dimo T, Kamtchouing P, et al. Ethanol extract of Peperomia pellucida ( Piperaceae ) promotes fracture healing by an anabolic effect on osteoblasts. J Ethnopharmacol. 2013;148(1):62-8. https://doi. org/10.1016/j.jep.2013.03.063; PMid:23578859.

16. Saputri FC, Mun'im A, Lukmanto D, Aisyah SN, Rinandy JS. Inhibition of angiotensin converting enzyme (ACE) activity by some Indonesia edible plants. Int J Pharm Sci Res. 2015;6(3):1054-9.

17. Kurniawan A, Saputri FC, Ahmad I, Mun'im A. Isolation of angiotensin converting enzyme (ACE) inhibitory activity quercetin from Peperomia pellucida. Int J PharmTech Res. 2016;9(7):115-21.

18. WangL, Weller CL. Recent advances in extraction of nutraceuticals from plants. Trends Food Sci Technol. 2006;17(6):300-12. https://doi.org/10.1016/j. tifs.2005.12.004.

19. Belwal T, Bhatt ID, Rawal RS, Pande V. Microwave-assisted extraction ( MAE ) conditions using polynomial design for improving antioxidant phytochemicals in Berberis asiatica Roxb. ex DC. leaves. Ind Crop Prod. 2017;95:393-403. https:// doi.org/10.1016/j.indcrop.2016.10.049.

20. Routray W, Orsat V. MAE of phenolic compounds from blueberry leaves and comparison with other extraction methods. Ind Crop Prod. 2014;58:36-45 https://doi.org/10.1016/j.indcrop.2014.03.038.

21. 21. Sochor J, Ryvolova M, Krystofova O, Salas P, Hubalek J, Adam V, et al. Fully automated spectrometric protocols for determination of antioxidant activity: Advantages and disadvantages. Molecules 2010;15(12):8618-40. https://doi. org/10.3390/molecules15128618; PMid:21116230

22. Grassmann J. Terpenoids as plant antioxidants. Vitam Horm. 2005;72:505-35 
https://doi.org/10.1016/S0083-6729(05)72015-X.

23. Balasuriya BWN, Rupasinghe HPV. Plant flavonoids as angiotensin converting enzyme inhibitors in regulation of hypertension. Funct Foods Heal Dis. 2011;1(5):172-88.

24. Men R, Li N, Xing Y, Tang Y, Tan C. Chemical constituents and ACE inhibitory activity of desert plant Suaeda physophora Pall. Acta Pharm Sin B. 2013;3(5):32832. https://doi.org/10.1016/j.apsb.2013.07.003.

25. Sharifi N, Souri E, Ziai SA, Amin G AM. Discovery of new angiotensin convert- ing enzyme (ACE) inhibitors from medicinal plants to treat hypertension using an in vitro assay. Daru. 2013;21(1):74. https://doi.org/10.1186/2008-2231-21-74 ; PMid:24359711 PMCid:PMC3896793.

26. Susmita DAS, Bratati DE. Evaluation of angiotensin I-converting enzyme (ACE) inhibitory potential of some underutilized indigenous fruits of West Bengal using an in vitro model. Fruits 2013;68:499-506. https://doi.org/10.1051/ fruits/2013092.

Article History: Submission Date: 21-12-16; Revision Date:07-01-17; Accepted Date:21-01-17.

Cite this article: Mun'im A, Nurpriantia S, Setyaningsih R, Syahdi RR. Optimization of Microwave-Assisted Extraction of Active Compounds, Antioxidant Activity and Angiotensin Converting Enzyme (ACE) Inhibitory Activity from Peperomia pellucida (L.) Kunth. JYoung Pharm. 2017;9(1):s73-s8. 